\title{
Ovarian risk factors of female infertility by transvaginal ultrasonography
}

\author{
SYEDA KHADIJA- TUL-SUGHRA ${ }^{1}$, SYED AMIR GILANI ${ }^{1}$, ASIF HANIF ${ }^{1}$, SABAR BUTT ${ }^{2}$, ZAIN-UL-HASAN ${ }^{1}$, WAHEEDA \\ AWAIS $^{1}$ \\ ${ }^{1}$ University Institute of Radiological Sciences, University of Lahore, Lahore, Pakistan. \\ ${ }^{2}$ Sabari ultrasound training institute Faisalabad, Pakistan. \\ Correspondence to Syeda Khadija-Tul-Sughra Murrium, Email: syyedakhadija55@gmail.com, Cell: +92-0335-1543555
}

\begin{abstract}
Aim: To determine the Ovarian risk factors of female infertility by transvaginal ultrasonography Study design: Cross sectional validation study

Methods: The study comprised women visiting the department with unexplained infertility for treatment during the period of 2018 to 2020 . A total of 550 cycles were inducted primarily referred for ovarian assessment by ultrasound with patent tubes and normal utero-ovarian morphology. All those women having no conception with normal semen analysis of their husbands. Male factor infertility was also excluded. Baseline transvaginal sonography (TVS) was performed at proliferative phase, of the cycle. Mature follicles were studied by TVS. On an individual basis, the following parameters, that is, follicle size, ovarian volume and ovarian artery Doppler PI, RI were studied. Follicle size and ovarian artery Doppler flow were highly significant for a pregnancy.

Results: In this research two types of infertility was compared with normal group as for as the primary infertile females were $99(18.00 \%)$ and secondary infertile females were $144(26.18 \%)$ and normal were $307(55.82 \%)$. Out of 550 patients $243(44.18 \%)$ patients were infertile and $307(55.82 \%)$ were normal. Discussed in this research.

Conclusions: Ovarian ultrasound assessment proved to be a simple, noninvasive and authentic to predict the ovarian environment and thereby helping in the prediction of the outcome in infertility.

Keywords: Infertility, Doppler ultrasonography, Transvaginal ultrasonography, Resistive index, Pulsatility index
\end{abstract}

\section{INTRODUCTION}

Sterility is a predominant condition and it is a critical clinical, social and general medical issue that influences $10-15 \%$ of couples during their life time ${ }^{1}$. The World Health Organization's characterize infertility depends on a year of attempting to consider. World Health Organization (WHO) assessed that in 2010, 48.5 million couples overall couldn't have a kid. They found that $1.9 \%$ of ladies aged $20-44$ who needed a baby couldn't have their first live birth and $10.5 \%$ of ladies who had recently conceived an offspring couldn't have another infant following five years of endeavoring. This addressed a $0.1 \%$ and $0.4 \%$ diminishing from 1990, respectively ${ }^{2}$. Despite the fact that Pakistan is among the present most crowded nations of the world, and has a populace development pace of around $2 \%$, the predominance of barrenness in Pakistan is $22 \%$ with 4 $.0 \%$ of essential fruitlessness and $18.0 \%$ of auxiliary barrenness. Essential barrenness is 2 to $5 \%$, while optional fruitlessness, showing suspension of additional richness and predominance pace of $20 \%$, globally ${ }^{3}$. Uneasiness, sadness and stoutness is driving reason for fruitlessness as indicated by one assessment practically $86.8 \%$ of barren ladies experienced nervousness and $40.8 \%$ from depression ${ }^{4}$. Transvaginal ultrasonography assumes a fundamental part in present day barrenness determination. It is utilized to look at the presence of ovaries and follicles, ovarian volume, ovarian course Doppler stream (resistive and pulsatility file), follicular size and shape. Assessing the follicular size at a particular time during the monthly cycle is vital in the fruitless females. Mid in the cycle, at proliferative stage the follicle ought to seem smooth, anechoic and most extreme size which ought to be < $30 \mathrm{~mm}$ is consider. This trademark is wanted at the hour of ovulation. The cyclic changes, intermittent assessment of the follicles during the cycle permits appraisal of its capacity, size, and receptivity. ${ }^{5}$ Transvaginal sonography (TVS) and

Received on 17-12-2020

Accepted on 24-03-2021
Transabdominal sonography (TAS) can distinguish ovaries. Ovaries are normally portrayed as elliptical designs estimating around $3 \mathrm{~cm}$ in long-pivot and $2 \mathrm{~cm}$ in foremost and back or cross over measurement $1 \mathrm{~cm}$. On calculated long-pivot filters, they are quickly average to the pelvic vessels. Estimations of the long, short and A/P measurement of the ovary decides ovarian volume by the ellipsoid equation (length $x$ stature $\times$ width $\times 0.5=$ volume in $\mathrm{cm} 3$ ). In premenopausal ladies, the ordinary ovary goes from 10 to $12 \mathrm{~cm}^{3}$ in volume. They are especially all around portrayed when they contain a develop follicle that is ordinarily in 1.5 to $2.0 \mathrm{~cm}$ range ${ }^{6}$. The size of the ovary is identified with the patient's age and period of follicular turn of events. The ovarian scoring framework for multiplication involves the accompanying boundaries, taken in mid-cycle at proliferative stage on twelfth to fourteenth day of menstrual cycle: 1. Ovarian volume (Right, left) 2. Follicle size (Right, left) 3. Ovarian course Doppler. (Right, left). At a pattern assessment, US checking can distinguish ovarian anomalies, for example, follicular pimples or adnexal masses that should be tended to progress of time. Besides, antral follicles gives a clue into the possibility of success ${ }^{7}$. Polycystic ovaries additionally cause barrenness. Ultrasound rules are utilized to recognize an ordinary ovary from polycystic ovaries ${ }^{8}$. Ultrasound gives another significant bit of leeway, the capacity to depiction blood stream with Doppler imaging Color Doppler in infertile females can show the example and measure of blood stream (focal, fringe, bountiful, or insufficient), and ghostly Doppler strategies can portray the stream in more detail ${ }^{9}$.

The pattern or absence of blood flow will facilitate arrival at the correct diagnosis, such as the characteristic circumferential "ring of fire" around a corpus luteum. Doppler imaging, both color and spectral, permit the study of the characteristics of developing follicles. These Doppler studies performed on the day of ovulation ${ }^{10}$. 


\section{MATERIAL AND METHODS}

The ovarian biophysical profile (OBPP) was determined by applying the ovarian scoring system for reproduction (OSSR). Transvaginal ultrasound was used as first line examination in infertile females, with empty bladder, for evaluation of follicle size, ovarian volume and ovarian artery Doppler flow. A Cross sectional validation study was conducted in 2019-2021. Data was collected from multi centers of Lahore city. The study subjects included 550 normal and infertile females. Infertile females were clinically diagnosed primarily or secondary infertility and referred for ovarian biophysical profile by transvaginal ultrasound with patent tubes and normal uterine biophysical profile. Method of collection of data following a written informed consent as per the WHO guidelines from couples willing to be a part of the study, the history, examination and investigation findings were noted. All studies were performed through spontaneous ovarian cycles every 1214 days from the onset of menstruation, to include the early proliferative phase of the ovarian cycle. TVS suggestive of the abnormalities of the ovaries, or any other pelvic pathology were excluded. Male factor infertility was also excluded. Monitoring was then attempted. Follicular development can be straightforwardly observed with 2D ultrasound, since the follicular measurement increments during improvement in the follicular stage. Most clinicians measure the follicles at gauge or first line examination, volume of the ovaries and RI, PI of ovarian courses. Indicative methodology were finished by shading and force Doppler investigation of intra-ovarian vascularization, with $\mathrm{PI}$ and $\mathrm{RI}$, to break down vascular design of ovaries. Momentarily, transvaginal longitudinal sweeps were performed utilizing an imaging transducer 7-12 $\mathrm{MHz}$ to envision the ovaries. Mean follicular breadth was noted to evaluate follicular size. The OBPP score was assessed. All information were genuinely examined. The ovarian stromal vascularization was enrolled by shading Doppler and shading Doppler energy imaging with 7-12 MHz endovaginal ultrasound test. CD imaging was utilized for planning the ovarian stromal veins. The cursor was situated on the most unmistakable ovarian stromal vein, with the entryway width however much as could be expected shut to the breadth of the vessel, after which the beat wave was begun. Estimating was performed when the base of three clear waveforms was acquired. Pulsatility list $(\mathrm{PI})$, resistive record $(\mathrm{RI})$ were estimated. The equivalent sonographer played out all ultrasound assessment.

\section{RESULTS}

The mean age of fertile females was $29.14 \pm 2.81$ years and median 29.0(7.00) and infertile females was31.36 \pm 5.26 and median was $31.0(6.00)$ respectively. The mean age of fertile was less than infertile and statistically significant among the two study groups of fertile and infertile. P-value $<0.001$. The mean right ovarian volume of fertile females was $10.13 \pm$ $2.10 \mathrm{ml}$ and median $10.00(2.00) \mathrm{ml}$, in infertile female mean was $10.43 \pm 3.66 \mathrm{ml}$ and median was $10.00(3.00) \mathrm{ml}$ whereas, the mean right ovarian volume of fertile females was statistically same as the infertile females $(P$-value $=0.535)$. The mean left ovarian volume of fertile females was $10.73 \pm 1.87 \mathrm{ml}$ and median $11.00(3.00) \mathrm{ml}$ and in infertile females $10.72 \pm$ $3.15 \mathrm{ml}$ and median $10.00(4.00) \mathrm{ml}$ whereas, the mean left ovarian volume of fertile and infertile was statistically same among the two study groups. ( $P$-value $=0.059)$. The mean follicle size in right ovary in fertile females was $2.15 \pm 0.75 \mathrm{~cm}$ and median $2.40(0.70)$ ad in infertile females was $1.45 \pm 0.80 \mathrm{~cm}$ and median $1.00(1.30)$ respectively. The mean follicle size in left ovary in fertile females was $2.01 \pm 0.78 \mathrm{~cm}$ and median $2.30(1.10)$ in infertile females was $1.23 \pm 0.71 \mathrm{~cm}$, and median 1.00(1.20) respectively. The mean follicle size of right and left ovary in fertile and infertile was statistically highly significant among the two study groups of fertile and infertile. The $p$-value $<0.001$. The mean right ovarian artery resistive index in fertile females was $0.82 \pm 0.29$ median $0.78(0.22)$ and in infertile females mean was $1.02 \pm 0.56$ and median $0.95(0.42)$ respectively. The mean resistive index of left ovarian artery in fertile females was $0.79 \pm 0.21$ and median $0.77(0.17)$ and in infertile females mean was $1.00 \pm 0.50$ and median was $0.86(0.27)$ respectively. The mean resistive index of right and left ovarian artery was statistically highly significant among the two study groups of fertile and infertile. The pvalues $<0.001$. The mean pulsatility index of right ovarian artery in fertile females was $2.84 \pm 0.85$ and median was 2.88 (0.99) and in infertile females mean was $2.82 \pm 0.93$ and median 2.86(1.63) respectively. The mean pulsatility index of right ovarian artery was statistically insignificant among the two study groups of fertile and infertile. The $p$ - values 0.667 . The mean pulsatility index of left ovarian artery in fertile females was $2.92 \pm 0.56$ and median $3.00(0.91)$ and in infertile females mean was $3.14 \pm 0.77$ and median 3.08 (1.31) respectively. The mean pulsatility index of left ovarian artery was statistically highly significant among the two study groups of fertile and infertile. The $p$-values $<0.001$.

Case 1: Primary infertility of female with enlarge volume of the ovaries and small immature follicles at periphery with central echogenic stroma.
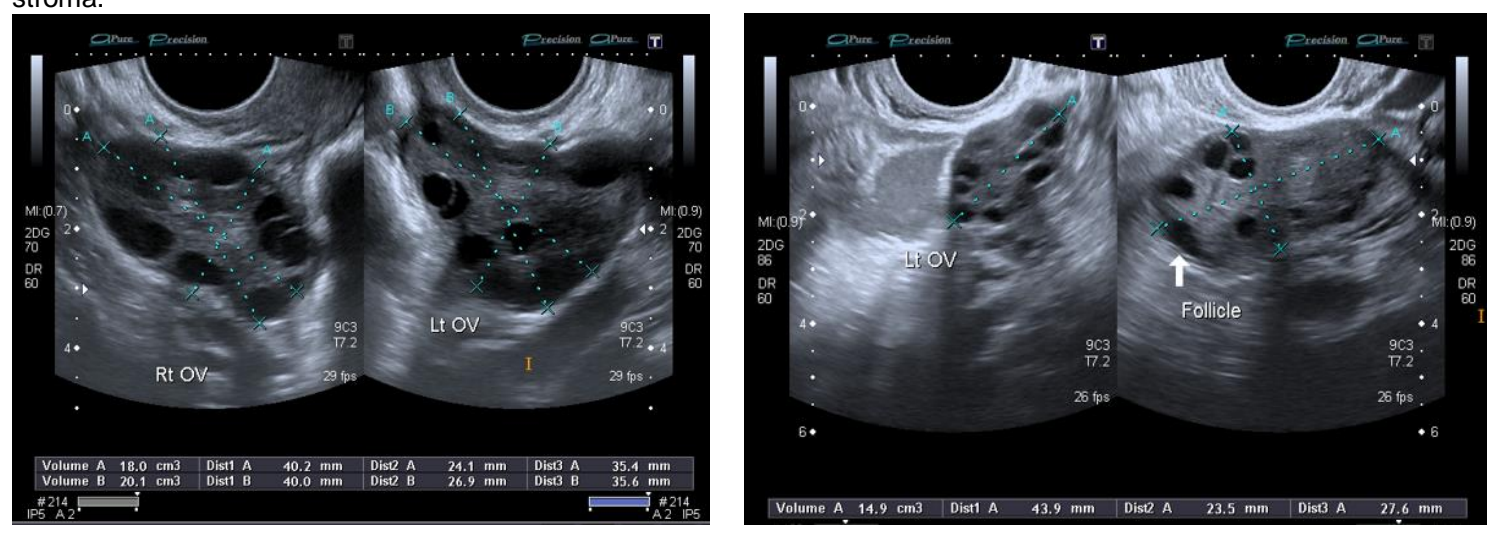
Case 2: Secondary infertility enlarged ovaries with small immature follicles $<1 \mathrm{~cm}$ at periphery of the ovaries with central echogenic stroma.
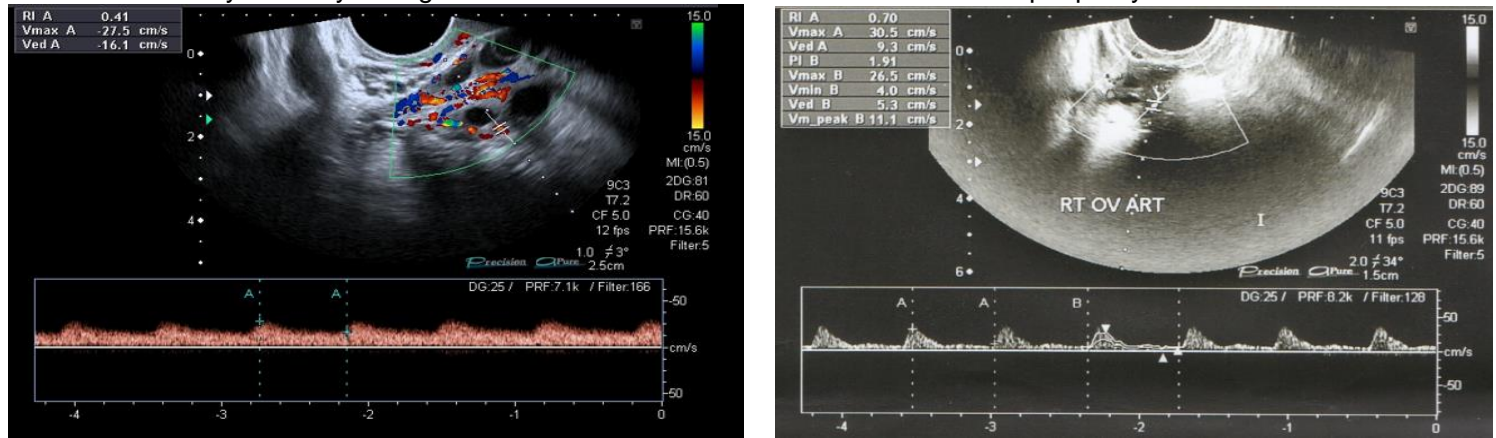

Case 3: Shows the $\mathrm{RI}=0.41$ of ovarian artery in fertile female.

Case 4: shows the $\mathrm{RI}=0.70, \mathrm{PI}=1.91$ in primary infertile female at $12^{\text {th }}$ day of her menstrual cycle.

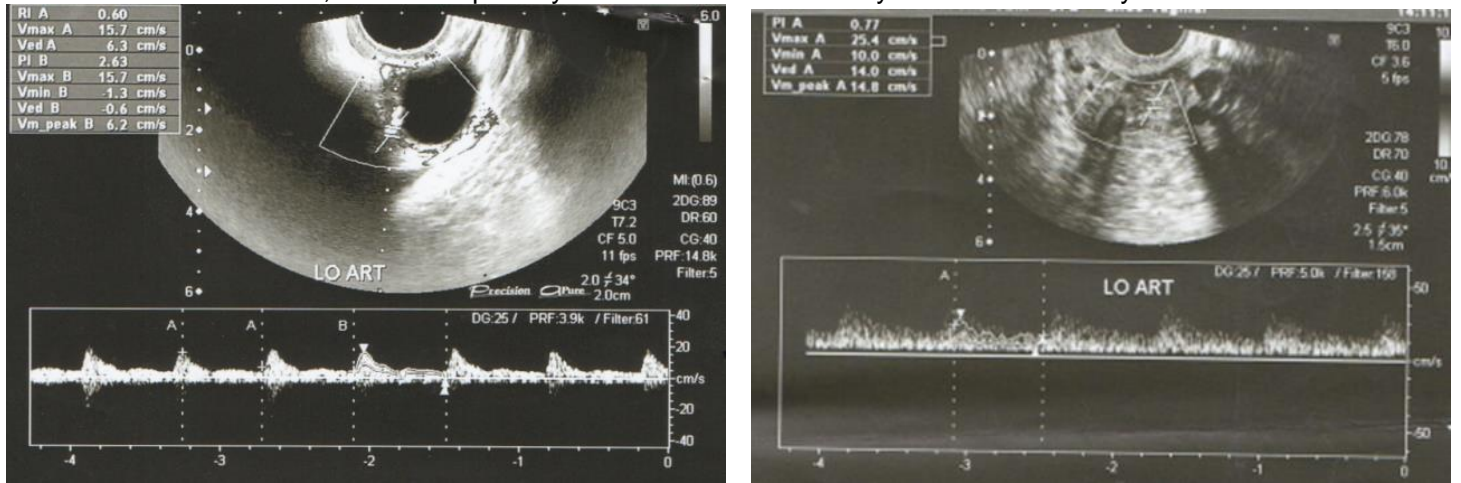

Case 5: Shows the ovarian artery doppler vasularity with mature follicle Normal $\mathrm{Rl}=0.60$ and $\mathrm{ncreased} \mathrm{Pl}=2.63$ in secondary infertile female. Case 6: Shows the $\mathrm{PI}=0.77$ of left ovarian artery in primary infertile female at $12^{\text {th }}$ day of menstrual cycle

Table 1: Variables in the Equation

\begin{tabular}{|l|l|c|c|c|c|c|c|}
\hline & B & S.E. & Wald & df & Sig. & Exp(B) \\
\hline Step 0 & Constant & .234 & .086 & 7.413 & 1 & .006 & 1.263 \\
\hline
\end{tabular}

Table 2: Variables not in the Equation

\begin{tabular}{|c|c|c|c|c|c|}
\hline \multicolumn{3}{|c|}{ (2) } & Score & df & Sig. \\
\hline \multirow[t]{11}{*}{ Step 0} & \multirow[t]{10}{*}{ Variables } & PT.AGE & 25.404 & 1 & .000 \\
\hline & & RT.O.V & 1.420 & 1 & .233 \\
\hline & & LT.O.V & .004 & 1 & .948 \\
\hline & & F.S.RT.O & 93.731 & 1 & .000 \\
\hline & & F.S.LT.O & 117.300 & 1 & .000 \\
\hline & & RT.OA.RI & 29.558 & 1 & .000 \\
\hline & & RT.OA.PI & .068 & 1 & .794 \\
\hline & & LT.OA.RI & 40.858 & 1 & .000 \\
\hline & & LT.OA.PI & 14.254 & 1 & .000 \\
\hline & & Total & 132.556 & 1 & .000 \\
\hline & \multicolumn{2}{|c|}{ Overall Statistics } & 219.023 & 10 & .000 \\
\hline
\end{tabular}

Table 3: Variables in the Equation

\begin{tabular}{|c|c|c|c|c|c|c|c|c|}
\hline \multirow{2}{*}{ Step 1} & & \multirow[b]{2}{*}{ S.E. } & \multirow[b]{2}{*}{ Wald } & \multirow[b]{2}{*}{ df } & \multirow[b]{2}{*}{ Sig. } & \multirow[b]{2}{*}{$\operatorname{Exp}(B)$} & \multicolumn{2}{|c|}{ 95.0\% C.I. for EXP(B) } \\
\hline & & & & & & & Lower & Upper \\
\hline PT.AGE & -.123 & .025 & 24.798 & 1 & .000 & .884 & .842 & .928 \\
\hline RT.O.V & -.057 & .076 & .564 & 1 & .453 & .945 & .814 & 1.096 \\
\hline LT.O.V & .108 & .081 & 1.784 & 1 & .182 & 1.115 & .951 & 1.307 \\
\hline F.S.RT.O & .525 & .144 & 13.334 & 1 & .000 & 1.690 & 1.275 & 2.240 \\
\hline F.S.LT.O & .988 & .158 & 38.925 & 1 & .000 & 2.686 & 1.969 & 3.664 \\
\hline RT.OA.RI & .529 & .343 & 2.377 & 1 & .123 & 1.697 & .866 & 3.323 \\
\hline RT.OA.PI & .404 & .185 & 4.742 & 1 & .029 & 1.497 & 1.041 & 2.153 \\
\hline LT.OA.RI & -.933 & .475 & 3.861 & 1 & .049 & .393 & .155 & .998 \\
\hline LT.OA.PI & -.173 & .212 & .663 & 1 & .415 & .841 & .555 & 1.275 \\
\hline Total & .334 & .078 & 18.248 & 1 & .000 & 1.396 & 1.198 & 1.627 \\
\hline Constant & -2.204 & 1.603 & 1.890 & 1 & .169 & .110 & & \\
\hline
\end{tabular}

a. Variable(s) entered on step 1: PT.AGE, RT.O.V, LT.O.V, F.S.RT.O, F.S.LT.O, RT.OA.RI, RT.OA.PI, LT.OA.RI, LT.OA.PI, Total. 


\section{DISCUSSION}

Wellbeing strategy creators are progressively being encouraged to start to coordinate fruitlessness avoidance, care and treatment into the work being done to fortify maternal, infant and conceptive medical care frameworks. $20 \%$ of infertile cases are brought about by ovarian elements. Ultrasound is utilized to screen the size, number, development, and development of ovarian follicles ${ }^{11}$. Transvaginal Sonography can distinguish follicles as little as possible assistance follow the ordinary follicular development pace of 2 $\mathrm{mm}$ each day. A follicle is experienced when it arrives at a breadth of between 2 to $2.7 \mathrm{~cm}^{12}$. Ovarian hyperstimulation is a significant confusion of hormonal incitement. Another ovarian-related reason for fruitlessness is polycystic ovarian sickness $(P O D)^{13}$, called Stein-Leventhal syndrome, is an intricate endocrine issue of obscure etiology exposed by numerous, little normally more diffident than $1 \mathrm{~cm}$ cystic areas. These cystic areas are thought to address graafian follicles. Sonographic highlights of polycystic ovaries integrate twosided (normally symmetric) ovarian extension (mean, 13 to 14 $\mathrm{cm}$ ), numerous 2-to 6-mm growths, and nonattendance of pimples more noteworthy than $1.5 \mathrm{~cm}$ in breadth, smooth shapes, and hyperechoic ovarian stroma ${ }^{14}$. The little blisters might be incidentally found or scattered all through the ovarian parenchyma. The presence of ordinary ovaries doesn't bar POD, for up to $33 \%$ of patients with clinical signs of POD have sonographically typical ovaries ${ }^{15}$. Follicular size receptivity assumes a significant part in implantation of incipient organism and assessment of follicular size receptivity stays a test in clinical practice. Indeed, even in the event of patients where the issue of fruitlessness can be settled through restorative or careful mediations, hindrances to treatment do exist, which may extensively be assembled into three primary classifications: openness, monetary expense, and social/cultural components. In non-industrial nations like Pakistan, each of the three exist simultaneously. The present examination was finished to choose ovarian risk components of female fruitlessness by transvaginal ultrasonography among women going to the gynecology outpatient division, and perceive the rate course of ovarian segments. An examination was directed by MOHAMMED A, et al in 2020 he talks about in his exploration that the ovarian anomalies $23.3 \%$ reason fruitlessness. It incorporate the ovarian dysgenesis, untimely ovarian disappointment, androgenic problems and polycystic ovarian syndrome ${ }^{16}$.

Our examination shows the mean follicle size of healthy females was more prominent than the mean follicle size of unhealthy females. The mean follicle size in prolific and barren was genuinely huge among the two examination gatherings of rich and fruitless. Shaheen $R$ et al led an examination in Pakistan in 2010 his outcomes shows that the Ovulatory disappointment in Pakistan are $118(22.09 \%)^{15}$. According to an examination directed F.M. Severi, C. Bocchi, in 2012 uncover that lacking follicle can be consider as a principle fruitfulness deciding variable. In his examination they talked about the size of the follicles as they develop, follicles ordinarily measure from 17 to $25 \mathrm{~mm}$ in normal internal dimension ${ }^{17}$. A research was led in 2013 by Neeta Singh et al. in unconstrained patterns of 222 ladies, they examined that creating follicles bound to ovulate increment in size 2 to $3 \mathrm{~mm} /$ day and arrive at a most extreme width of 16 to $33 \mathrm{~mm}$ before ovulation. Overwhelm follicle within the ovary can be perceived by transvaginal shading Doppler by day eighth and tenth of the cycle, the follicle develops to around 20 to $24 \mathrm{~mm}^{18}$.
Asim kurjeck conducted an examination in 1991 by transvaginal Doppler stream in evaluation of ovarian and uterine veins in infertile ladies. In anovulatory cycles, ovarian corridor stream speed is generally distinguished when the predominant follicle arrives at 12 to $15 \mathrm{~mm}$. The obstruction file is $0.54 \pm 0.04$ and furthermore decays on the day preceding ovulation. A nadir of $0.44 \pm 0.04$ is arrived at 4 to 5 days after the fact and gradually ascends to $0.050 \pm 0.04$ before menstruation ${ }^{19}$.

Richard Fleming ${ }^{20}$ in 2015 audit the article wherein he talked about Oocyte number and quality decay with age; notwithstanding, richness changes significantly even among ladies of a similar age. Transvaginal ultrasound is needed to decide AFC by imaging and physically estimating the width of all little antral follicles and checking those somewhere in the range of 2 and $10 \mathrm{~mm}$ in measurement. Ladies with a low ovarian save are bound to react to ovarian incitement with an unassuming level of follicular advancement ('helpless responders') and may require more noteworthy administration of their assumptions for result achievement ${ }^{21}$.

Expanded age is related with diminished ovarian volume. Transvaginal estimation of ovarian volume is snappy, precise and financially savvy. Diminished ovarian volume and low number of antral follicles of $2-10 \mathrm{~mm}$ are indications of ovarian maturing that might be noticed sooner than an ascent in $\mathrm{FSH}$ focuses. Akmal El-Mazny et al led an examination in 2016 his exploration exhibit the ovarian artery $\mathrm{PI}$ in benchmark group was $1.6 \pm 0.4$ and $\mathrm{RI} 0.85 \pm 0.11$ in ordinary ripe females, their outcomes showed that there were no critical contrasts seen in the ovarian Doppler files between endometrioma-containing ovaries and contralateral ovaries ${ }^{22}$. Steer et al., showed that expanded uterine corridor blood stream obstruction can cause unexplained infertility ${ }^{23}$. In another investigation, Taylor et al., found that patients going through controlled ovarian hyperstimulation have expanded ovarian supply route blood stream opposition and low reaction to in vitro fertilization ${ }^{24}$. Temizkan et al., showed that hyperprolactinemia had a vasoconstrictor impact and was identified with expanded blood stream resistance ${ }^{25}$.

In any case, an examination led by Ranko kutlesi in 2009 his outcomes shows that the RI of the left ovary at the time of $<35$ years $0.60 \pm 0.11 \mathrm{RI}$ right ovarian artery $0.64 \pm 0.10 \mathrm{RI}$, left ovarian conduit at the period of $\geq 35$ years $0.66 \pm 0.12^{26}$.

In December 1989 Michael C. W. Scholtes, M.D directed an investigation on Uterine and ovarian stream speed waveforms in the typical period: a transvaginal Doppler study non prevailing ovarian artery $\mathrm{PI}=0.39 \pm 0.24$ Dominant ovarian course pulsatility record $=0.44 \pm 0.24$ Non predominant uterine conduit $\mathrm{PI}=+0.05 \pm 0.15$. Prevailing ovarian supply route versus non predominant ovarian conduit $=-0.57 \pm 0.1529$. The cut off estimations of $\mathrm{PI}, \mathrm{RI}$ between unexplained barrenness and fruitful gathering are $\geq 0.59$. Ovarian $\mathrm{PI}$ Mean $\pm S D$ $0.96 \pm 0.28$ and Ovarian RI Mean \pm SD $0.58 \pm 0.06$ in ordinary ripe females ${ }^{27}$.

\section{CONCLUSION}

In numerous societies, childless ladies endure separation, disgrace and ostracism. Our way of life requests that, for a lady to be socially acceptable, she ought to have in any event one natural kid. For some barren ladies, especially those with issues like small size follicle, abnormal size or hypoplastic ovaries expanded Doppler lists might be insignificant yet in the event that these risk factors can be treated with a lot of ladies can able to conceived. Services to assist infertile couples need 
to be integrated and holistic - beginning from the community level to demystify the cause and prevent infertility when possible, and to provide referral for affordable care if infertility is unavoidable.

\section{Limitations:}

- One of the difficulties in assessing the ovarian circulation is related to the numerous blood vessels identified by color Doppler within the ovarian stroma and around the follicles. In the present study, Doppler measurements were obtained from the blood vessels within the ovarian stroma that demonstrated the lowest resistance to flow. This approach does not take into account the number and distribution of the blood vessels within the ovary.

- Despite the fact that this study has limitations due to small number of patients, we believe it could become a base line and give guidance for other future studies.

- Ovarian artery pulsatility index decline after ovulation,

- $\quad \mathrm{PI}$ is lower in women with better endocrine response than poor response

- The number and size of stromal blood vessels increase with Follicular development

\section{REFERENCES}

1. Erdem K, Apay SE. A sectional study: the relationship between perceived social support and depression in turkish infertile women. International journal of fertility \& sterility. 2014 Oct;8(3):303-14.

2. Jacobson $M H$, Chin HB, Mertens AC, Spencer JB, Fothergill A, Howards PP. "Research on infertility: definition makes a difference" revisited. American journal of epidemiology. 2018 Feb 1;187(2):337-46.

3. Boivin J, Carrier J, Zulu JM, Edwards D. A rapid scoping review of fear of infertility in Africa. Reproductive health. 2020 Dec;17(1):13.

4. Khan A, Rehman IU, llyas M, Ahmad H, Marwat M, Khan G. FREQUENCY AND DETERMINANTS OF DEPRESSIVE ILLNESS AMONG INFERTILE WOMEN. Gomal Journal of Medical Sciences. 2018;16(3)

5. Stadtmauer LA, Tur-Kaspa I, editors. Ultrasound Imaging in Reproductive Medicine: Advances in Infertility Work-up, Treatment and ART. Springer; 2019 Jul 19.pp75-90.

6. Queenan JT, O'brien GD, Bains LM, Simpson J, Collins WP Campbell S. Ultrasound scanning of ovaries to detect ovulation in women. Fertility and sterility. 1980 Aug 1;34(2):99-105.

7. Kawamura K, Ishizuka B, Hsueh AJ. Drug-free in-vitro activation of follicles for infertility treatment in poor ovarian response patients with decreased ovarian reserve. Reproductive BioMedicine Online. 2020 Feb 1;40(2):245-53.

8. Teede $\mathrm{H}$, Misso M, Tassone EC, Dewailly $\mathrm{D}, \mathrm{Ng} E \mathrm{EH}$, Azziz $\mathrm{R}$, Norman RJ, Andersen M, Franks S, Hoeger K, Hutchison S. AntiMüllerian hormone in PCOS: a review informing international guidelines. Trends in Endocrinology \& Metabolism. $2019 \mathrm{Jul}$ 1;30(7):467-78

9. Oliveira ME, Fonseca JF, Vicente WR, Rodrigues NN, Vergani GB, Souza-Fabjan JM, Jamieson M, Cristescu A, Murawski M, Bartlewski PM. Are the spectral Doppler indices of ovarian arteries indicative of antral follicular development and predictive of ovulatory responses and embryo yields in superovulated ewes? Reproductive Biology. 2019 Dec 1;19(4):394-403.

10. D'Addario V, Kurjak A, Funduk-Kurjak B. Normal Ultrasound Female Pelvic Anatomy. In Pick Up and Oocyte Management Springer, Cham 2020 (pp. 37-47).
11. Collins JI, Woodward PJ. Radiological evaluation of infertility. In Seminars in Ultrasound, CT and MRI WB Saunders 1995 Aug 1 (Vol. 16, No. 4, pp. 304-316).

12. Blumenfeld Z, Yoffe N, Bronshtein M: Transvaginal sonography in infertility and assisted reproduction. Obstet Gynecol Surv 46:3649, 1990

13. Pache TD, Wladimiroff JW, Hop WC, Fauser BC. How to discriminate between normal and polycystic ovaries: transvaginal US study. Radiology. 1992 May;183(2):421-3.

14. Tabbakh GH, Lotfy I, Azab I, Rahman HA, Southren AL, Aleem FA. Correlation of the ultrasonic appearance of the ovaries in polycystic ovarian disease and the clinical, hormonal, and laparoscopic findings. American journal of obstetrics and gynecology. 1986 Apr 1;154(4):892-5.

15. Shaheen R, Subhan F, Sultan S, Subhan K, Tahir F. Prevalence of infertility in a cross section of Pakistani population. Pakistan Journal of Zoology. 2010 Aug 1;42(4).

16. MOHAMMED A, MAYSA SE, KERIAKOS N. Ultrasound Role in Management of Female Infertility. The Medical Journal of Cairo University. 2020 Sep 1;88(September):1523-30.

17. Severi FM, Bocchi C, Vannuccini S, Petraglia F. Ovary and ultrasound: from physiology to disease. Archives of Perinatal Medicine. 2012;18(1):7-19.

18. Singh N, Bahadur A, Malhotra N, Kalaivani M, Mittal S. Prospective analysis of ovarian reserve markers as determinant in response to controlled ovarian stimulation in women undergoing IVF cycles in low resource setting in India. Archives of gynecology and obstetrics. 2013 Sep 1;288(3):697-703.

19. Kurjak A, Kupesic-Urek S, Schulman H, Zalud I. Transvaginal color flow Doppler in the assessment of ovarian and uterine blood flow in infertile women. Fertility and sterility. 1991 Nov 1;56(5):870-3

20. Fleming R, Seifer DB, Frattarelli JL, Ruman J. Assessing ovarian response: antral follicle count versus anti-Müllerian hormone. Reproductive biomedicine online. 2015 Oct 1;31(4):486-96.

21. Lass A. Assessment of ovarian reserve: is there still a role for ovarian biopsy in the light of new data?. Human Reproduction. 2004 Mar 1;19(3):467-9.

22. El-Mazny A, Kamel A, Ramadan W, Gad-Allah S, Abdelaziz S, Hussein AM. Effect of ovarian endometrioma on uterine and ovarian blood flow in infertile women. International journal of women's health. 2016;8:677.

23. Steer CV, Tan SL, Mason BA, Campbell S. Midluteal-phase vaginal color Doppler assessment of uterine artery impedance in a subfertile population. Fertility and sterility. 1994 Jan 1;61(1):538.

24. Taylor KJ, Burns PN, Wells PN, Conway DI, Hull MG. Ultrasound Doppler flow studies of the ovarian and uterine arteries. BJOG: An International Journal of Obstetrics \& Gynaecology. 1985 Mar;92(3):240-6

25. Temizkan O, Temizkan S, Asicioglu O, Aydin K, Kucur S. Color Doppler analysis of uterine, spiral, and intraovarian artery blood flow before and after treatment with cabergoline in hyperprolactinemic patients. Gynecological Endocrinology. 2015 Jan 2;31(1):75-8.

26. Kutlešić R, Popović J, Vukomanović P, Stefanović M, Vidović B, Janjić Z, Vučetić D. color doppler and color doppler energy imaging and measurements of intraovarian vascularisation during luteal phase of menstrual cycle. Acta Facultatis Medicae Naissensis. 2009 Dec 1;26(4).

27. Scholtes MC, Wladimiroff JW, van Rijen HJ, Hop WC. Uterine and ovarian flow velocity waveforms in the normal menstrual cycle: a transvaginal Doppler study. Fertility and sterility. 1989 Dec $1 ; 52(6): 981-5$. 